\title{
Red meat and chicken consumption and its association with high blood pressure and obesity in South Korean children and adolescents: a cross-sectional analysis of KSHES, 2011-2015
}

Geum Hee Kim, ${ }^{1,6}$ Sang Won Shin², Juneyoung Lee ${ }^{3}$, Jun Hyun Hwang ${ }^{4}$, Soon-Woo Park ${ }^{4}$, Jin Soo Moon ${ }^{5}$, Hyun Jung Kim ${ }^{6}$ and Hyeong Sik Ahn ${ }^{6 *}$

\begin{abstract}
Background: The impact of meat consumption on high blood pressure (HBP) and obesity in children and adolescents is a subject of debate. The aim of this study was thus to evaluate the association between meat consumption and both HBP and obesity in this group.

Methods: We performed a cross-sectional analysis using nationally representative samples of children and adolescents aged 9, 12, and 15 years old $(n=136,739)$ who were included in the Korea School Health Examination Survey (KSHES) for the 2011-2015 period. Multiple linear and logistic regression analysis was used to determine the factors influencing systolic blood pressure (SBP), diastolic blood pressure (DBP), and body mass index $\left(\mathrm{BMl}, \mathrm{kg} / \mathrm{m}^{2}\right)$ levels, and to test the strength of these relationships.
\end{abstract}

Results: Adjusted for covariates, $6.3 \%$ of those subjects who consumed $>5$ servings of meat (including beef, pork, and chicken) per week were obese, compared with $9.1 \%$ of the subjects who consumed $<1$ serving of meat/wk (obesity adjusted odds ratio [OR]: 1.44; 95\% confidence interval [Cl]: 1.21-1.70; $P \leq 0.001$ ). Those who consumed $<1$ serving of meat/wk had an HBP prevalence of $8.2 \%$, compared with $7.2 \%$ for subjects who consumed $>5$ servings of meat/wk (systolic HBP adjusted OR: 1.30; 95\% Cl: 1.05-1.62; $P \leq 0.01$, diastolic HBP adjusted OR: 1.25; 95\% Cl: 1.02-1.54; $P<0.05$ ). Obese subjects were estimated to have a higher $\operatorname{SBP}(\beta=7.497, \mathrm{P}<0.001)$ and $\mathrm{DBP}(\beta=4.123, \mathrm{P}<0.001)$ than subjects who had no excess weight. Compared to subjects who consumed $>5$ servings of meat/wk, those who consumed $<3$ servings of meat/wk had a higher SBP $(\beta=0.574, P<0.001)$ and DBP $(\beta=0.376, P=0.003)$ after adjusting for BMI. The intake of milk, fruit, and vegetables was not associated with either SBP or DBP $(P>0.05)$. In contrast, BMI was significantly associated with milk, fruits, and vegetables $(P<0.01)$.

Conclusions: Among children and adolescents, a higher level of meat consumption was associated with lower SBP, $\mathrm{DBP}$, and BMl, and greater height, suggesting that consuming an appropriate amount of meat is important for healthy growth at a young age.

Keywords: Meat consumption, High blood pressure, Obesity, Children and adolescents

\footnotetext{
*Correspondence: iebm.ku@gmail.com

${ }^{6}$ Department of Preventive Medicine, College of Medicine, Korea University,

73, Inchon-ro, Seongbuk-gu, Seoul 02841, Republic of Korea

Full list of author information is available at the end of the article
} 


\section{Background}

The prevalence of high blood pressure (HBP) and obesity in children and adolescents has increased in the past years [1-8]. To lower blood pressure, several lifestyle changes are recommended, such as weight loss, exercise, and following a healthy diet [9]. An individual's diet is one of the main modifiable risk factors in the development of HBP $[2,9-16]$ and, in particular meat intake may play a role. On the one hand, many studies have found that the consumption of red meat and processed meat is associated with an increased risk of cardiovascular disease [17, 18]. On the other hand, meat and animal products are also important sources of protein, vitamins, minerals, and micronutrients that are vital to human health [19]. In fact, The Dietary Guidelines for Americans recommend the consumption of lean meat as part of a healthy diet and suggest there may be better ways to incorporate meat into healthy dietary patterns [20, 21]. In addition, recent research has shed light on the crucial role red meat has played in human evolution [15, 16, 19, 20, 22-26]. However, the association between nutrition and cardiovascular health [27] and the impact of meat consumption on HBP and obesity in both adults and children remain subjects of debate [28].

Therefore, the purpose of the present study was to examine the association between meat consumption and both high blood pressure and obesity in a sample of South Korean children and adolescents using a large, nationally representative sample.

\section{Methods}

\section{Data source and population}

We used 5 years of cross-sectional data from the nationally representative Korea School Health Examination Survey (KSHES, 2011-2015; 1,761 schools; $n=136,739$ students). The Office of Health Statistics collated data from three consecutive 3-year cycles of the KSHES (2009-2011, 2012-2014, and 2015-2017), collecting the data after obtaining written informed consent from the students and their parents. The KSHES is conducted every year by the Ministry of Education in accordance with various laws, including the School Health Act (Article 7), the Standards on Determination and Delivery of School Health Examination Results (Ministry of Education Notice No. 2010-7) for 17 cities and provinces in South Korea, and Guidelines on Electronic Processing and Management of Student Health Records (Ministry of Education Order No. 125). The results of the survey are released as official statistics by the government (Approval No. 11202) [29, 30].

The KSHES includes a stratified, multistage cluster probability sample of students in grades 1-12 who attend public school $[29,30]$. For the years used in this study, the first stage of sampling divided administrative districts into 42 to 45 strata depending on their size. The second stage extracted data from 742 to 764 schools, while the third stage extracted data from the first class of each grade. The students belonging to the classes selected in the third stage formed the final sample. Under the KSHES, students are required to visit the hospital for health examinations in grades $1,4,7$, and 10 . These students must visit medical institutions between April and July to receive their health examination, which includes physical development measurements. Therefore, our study sample included students who were in grade 4 (aged 9 years, $n=36,733$ ), grade 7 (aged 12 years, $n=49,280$ ) and grade 10 (aged 15 years, $n=50,726$ ), giving a total of 136,739 students from 1,761 schools. All of the anthropometric and BP measurements included in our study were taken at a hospital.

\section{Assessment of blood pressure}

Blood pressure (BP, $\mathrm{mmHg}$ ) was measured using an automated digital BP monitor (oscillometric devices models, OMRON MX3). All BP measurements were taken after the subjects had rested quietly in a sitting position for $5 \mathrm{~min}$. The right upper arm was placed at chest level, with the cuff covering at least two-thirds of the length of the arm. Blood pressure was measured using the right arm with an automated upper arm blood pressure monitor with an appropriate cuff size for a child's arm. Two BP readings were taken 5 min apart. Measures obtained by oscillometric devices that exceeded the 90th percentile were repeated with auscultation [31], the first $\mathrm{BP}$ reading discarded and the average of the subsequent measurements taken. The mean of the three SBPs and that of the three DBPs were calculated. Age-, sex-, and height-specific blood pressure cut-offs in Korean children and adolescents were used to define pre-hypertension and hypertension [32]. Using this definition, high blood pressure (HBP) was defined as a systolic BP (SBP) and/or a diastolic BP (DBP) above the 95th percentile for age, sex, and height.

\section{Assessment of body mass index}

Height and weight were measured with standardized procedures, as previously described (KSHES Questionnaires) $[29,30]$. Height was measured using a tool consisting of an upright measuring rod and a manual horizontal plate. The subjects were asked to remove their shoes and stand with their heels and buttocks touching the upright rod while resting their arms naturally by their sides. The readings were recorded in $0.1 \mathrm{~cm}$ units. Body weight was measured in kilograms with the subjects in an upright position without shoes, in minimal clothing, using a nationally certified, standardized digital scale (CAS, DB-150A). Body Mass Index (BMI) is defined as weight $(\mathrm{kg})$ divided by the square of height $\left(\mathrm{m}^{2}\right)$ [33]. Subjects were grouped into three categories of 
BMI: no excess weight, overweight, and obesity. Overweight was defined as 85 th $\leq \mathrm{BMI}<95$ th percentile and obesity was defined as $\mathrm{BMI} \geq 95$ th percentile (separately for each age and sex) according to the cutoff points of 2007 Korean growth charts [34]. Children and adolescents with a BMI below the 85 th percentile were defined as having no excess weight.

\section{Assessment of dietary variables}

The health behavior survey, which was conducted using a standardized questionnaire produced for the KSHES, and which was filled out at the participating hospitals, consisted of 28 questions that assessed 12 aspects of the respondents' dietary intake and physical activity. Students were asked to report how many times per week they consumed 5 categories of food: (1) meat, including beef, pork, and chicken, (2) dairy products, including milk, (3) fruit, (4) vegetables, and (5) breakfast. Response options were "daily," " 3 to 5 days per week," "1 to 2 days per week," and "never" [29, 30].

\section{Assessment of covariates}

We selected factors associated with HBP based on the current literature [2, 35-37]. Because geographic, socioeconomic, racial, and ethnic differences have been found in the HBP of children, adolescents, and adults in a number of studies $(27,30,31)$, our study adjusted for place of residence in terms of the 17 cities and provinces in South Korea covered by the survey. These areas were divided into two categories: urban (large, small, and medium-sized cities) and rural (islands, isolated areas, countryside districts, and small towns).

Subjects were also asked to report their physical activity and game/internet use. The survey asked "How many times a week do you exercise to the degree that you have shortness of breath and are sweaty?" with choices of "never," "1 to 2 days per week," "3 to 4 days per week," and " 5 to 6 days per week" and "Do you use the internet or play games for more than $2 \mathrm{~h}$ per day?" with "yes" or "no" as the two options.

\section{Statistical analysis}

The analysis was done using Statistical Analysis System (SAS version 9.4) and the IBM Statistical Package of Social Sciencess (SPSS version 21) software to deal with the complex sampling designs. We merged the available data from 2011 to 2015 and the analyses were adjusted for the strata, primary sampling units, and probability weights used in the complex sampling design of the KSHES. The demographics of the subjects were recorded as an unweighted sample size and a weighted percentage using composite sample descriptive statistics. For multivariable analysis, prevalence estimates and means were calculated for all variables and data sets. An analysis of variance (ANOVA) was conducted on continuous variables (height and $\mathrm{BMI}$ ), and categorical variables were expressed in frequency percentages and compared using chi-squared tests. Estimates of proportions, means (standard error of the mean, SEM), and percentiles were calculated. Multivariable analysis was conducted based on variables considered significant $(P<0.05)$ after univariate analysis. A multiple linear regression analysis was performed in order to identify variables that affect BP after controlling for sex, age, height, region, BMI, dietary patterns, and physical activity. Adjusted coefficients of determination (adjusted $R^{2}$ ), and the $\beta$ coefficient for the associations were estimated using multivariate linear regression models. In addition, adjusted odds ratios (ORs) with 95\% confidence intervals (CIs) for the associations were estimated using binary logistic regression models. We used logistic regressions to model the associations between four categories of meat consumption and two outcomes: HBP and obesity. In Model 1, we adjusted for sociodemographic covariates, including sex (girl or boy), age $(9,12$, and 15 years), height (centimeter), and region (rural or urban, and 17 cities and provinces in South Korea). In Model 2, we adjusted for BMI $\left(\mathrm{kg} / \mathrm{m}^{2}\right)$ when modelling $\mathrm{HBP}$ and for BP (mm $\mathrm{Hg}$ ) when modelling obesity. In Model 3, we further adjustd for dietary variables, including milk (quartiles), fruit (quartiles), vegetable (quartiles), and breakfast (quartiles). In Model 4, we further adjusted for physical activity and game/internet use.

\section{Results}

\section{Characteristics according to the frequency of meat consumption}

Of the 136,739 subjects, 9,918 (7.7\%) had high systolic and/or diastolic BP and 9,528 (7.6\%) were obese. Of those subjects who consumed meat (including beef, pork, and chicken) every day (intake $>5$ servings/wk), 7.2\% had HBP, compared to $8.2 \%$ for those who consumed little meat (intake $<1$ servings/wk). In addition, $6.3 \%$ of those subjects who consumed meat every day were obese, compared to 9.1\% in subjects who consumed little meat (Table 1).

The weighted percentage of systolic and diastolic HBP in subjects with no excess weight $(n=116,475)$ and with obesity $(n=9,746)$ according to the frequency of meat consumption is shown in Fig. 1 by age. Among 15-yearold adolescents with no excess weight, prevalence of systolic HBP was 4.2\% and diastolic HBP 5.9\% in those who consumed little meat, whereas it was $3.3 \%$ and $4.4 \%$ respectively in those who consumed meat every day (Fig. 1a and b). Meanwhile, among 15-year-old obese adolescents, prevalence of systolic HBP was 20.6\% and diastolic HBP $16.6 \%$ in those who consumed little meat, whereas it was $14.9 \%$ and $14.5 \%$ respectively in those who consumed meat every day (Fig. 1c and d). 
Table 1 Subject characteristics according to frequency of meat consumption per week

\begin{tabular}{|c|c|c|c|c|c|c|}
\hline \multirow{2}{*}{\multicolumn{2}{|c|}{$\begin{array}{l}\text { Merged 2011-2015 } \\
\text { Variables }\end{array}$}} & \multicolumn{4}{|c|}{ Consumption of meat per week } & \multirow[b]{3}{*}{$P$ - value } \\
\hline & & $<1$ & $1-2$ & $3-5$ & \multirow[t]{2}{*}{$>5$} & \\
\hline & & \multicolumn{3}{|c|}{$n(\%)^{c}$ or Mean (SEM) } & & \\
\hline Subjects $n(\%)^{c}$ & $136,739(100)$ & $4,801(3.4)$ & $70,193(51.8)$ & $48,538(37.1)$ & $10,165(7.7)$ & $<0.001$ \\
\hline Girls & $64,760(47.7)$ & $2,428(3.6)$ & $33,992(53.1)$ & $22,656(36.2)$ & $4,456(7.1)$ & $<0.001$ \\
\hline Boys & $71,979(52.3)$ & $2,373(3.1)$ & $36,201(50.7)$ & $25,882(37.9)$ & $5,709(8.3)$ & $<0.001$ \\
\hline $\operatorname{HBP} \cap(\%)^{c}$ & $9,918(7.7)$ & $387(8.2)$ & $5,190(7.7)$ & $3,610(7.8)$ & $731(7.2)$ & $<0.001$ \\
\hline Systolic HBP & $6,075(4.8)$ & $259(5.6)$ & $3,287(5.0)$ & $2,036(4.6)$ & $405(4.3)$ & $<0.001$ \\
\hline Diastolic HBP & $6,704(5.3)$ & $245(5.4)$ & $3,302(5.2)$ & $2,458(5.4)$ & $520(5.1)$ & $<0.001$ \\
\hline Obesity, $n(\%)^{c}$ & $9,528(7.6)$ & $399(9.1)$ & $5,337(8.2)$ & $3,203(6.9)$ & $589(6.3)$ & $<0.001$ \\
\hline 9 years & \multicolumn{5}{|c|}{ Anthropometric characteristics } & \\
\hline \multirow[t]{7}{*}{$n=36,733$} & Height, cm & $138.80(0.2)$ & $138.90(0.1)$ & $138.61(0.1)$ & $139.10(0.3)$ & 0.007 \\
\hline & $\mathrm{BMI}, \mathrm{kg} / \mathrm{m}^{2}$ & $18.53(0.1)$ & $18.46(0.0)$ & $18.34(0.0)$ & $18.29(0.1)$ & $<0.001$ \\
\hline & Obesity, $n(\%)^{c}$ & $138(9.8)$ & $1,736(7.9)$ & $694(7.0)$ & $53(6.2)$ & 0.001 \\
\hline & Blood pressure & & & & & \\
\hline & Systolic BP, mmHg & $99.64(0.4)$ & $99.00(0.2)$ & $99.13(0.3)$ & $98.97(0.6)$ & 0.004 \\
\hline & Diastolic BP, mmHg & $60.48(0.3)$ & $60.22(0.2)$ & $60.44(0.2)$ & $60.08(0.6)$ & 0.114 \\
\hline & $\mathrm{HBP}, n(\%)^{c}$ & $106(7.1)$ & $1,576(6.9)$ & $657(6.6)$ & $58(6.4)$ & $<0.001$ \\
\hline 12 years & \multicolumn{5}{|c|}{ Anthropometric characteristics } & \\
\hline \multirow[t]{7}{*}{$n=49,280$} & Height, cm & $156.99(0.2)$ & $157.28(0.1)$ & $157.51(0.1)$ & $157.92(0.2)$ & $<0.001$ \\
\hline & $\mathrm{BMI}, \mathrm{kg} / \mathrm{m}^{2}$ & $20.59(0.1)$ & $20.48(0.0)$ & $20.14(0.0)$ & $20.13(0.1)$ & $<0.001$ \\
\hline & Obesity, $n\left(\%^{c}\right.$ & $163(8.5)$ & $2,117(8.1)$ & $953(6.0)$ & $128(5.5)$ & 0.001 \\
\hline & Blood pressure & & & & & \\
\hline & Systolic BP, mmHg & $105.08(0.4)$ & $105.22(0.2)$ & $105.17(0.2)$ & $105.33(0.3)$ & 0.327 \\
\hline & Diastolic BP, mmHg & $63.32(0.2)$ & $63.33(0.1)$ & $63.39(0.1)$ & $63.20(0.2)$ & 0.204 \\
\hline & $\mathrm{HBP}, n(\%)^{c}$ & $172(7.9)$ & $2,023(7.7)$ & $1,111(7.4)$ & $158(6.6)$ & $<0.001$ \\
\hline 15 years & \multicolumn{5}{|c|}{ Anthropometric characteristics } & \\
\hline \multirow[t]{7}{*}{$n=50,726$} & Height, cm & $165.72(0.4)$ & $166.31(0.2)$ & $166.38(0.2)$ & $166.71(0.2)$ & 0.007 \\
\hline & $\mathrm{BMI}, \mathrm{kg} / \mathrm{m}^{2}$ & $21.96(0.1)$ & $21.90(0.0)$ & $21.74(0.0)$ & $21.64(0.0)$ & $<0.001$ \\
\hline & Obesity, $n(\%)^{c}$ & $98(9.2)$ & $1,484(8.6)$ & $1,556(7.4)$ & $408(6.6)$ & 0.001 \\
\hline & \multicolumn{5}{|l|}{ Blood pressure } & \\
\hline & Systolic BP, mmHg & $109.21(0.5)$ & $109.29(0.2)$ & $109.00(0.2)$ & $108.71(0.3)$ & 0.004 \\
\hline & Diastolic BP, mmHg & $65.55(0.3)$ & $65.70(0.1)$ & $65.55(0.1)$ & $65.28(0.2)$ & 0.114 \\
\hline & $\mathrm{HBP}, n(\%)^{\mathrm{c}}$ & $109(10.2)$ & $1,591(8.8)$ & $1,842(8.7)$ & $515(7.5)$ & $<0.001$ \\
\hline
\end{tabular}

${ }^{a}$ Cross-sectional data from the Korea School Health Examination Survey (2011-2015, 1761 schools)

${ }^{\mathrm{b}} P$-value, using chi-squared test for $n(\%)$, ANOVA for mean (standard error of the mean, SEM)

'Unweighted sample size and weighted percentage. In addition, sample sizes vary because of missing data

\section{Factors associated with BMI}

Table 2 presents factors associated with BMI, including place of residence, which were simultaneously adjusted using multiple linear regression (girls: $R^{2}=0.231$; boys: $R^{2}=0.191$ ). Subjects with systolic HBP were estimated to have a higher BMI (girls: $\beta=1.878$; boys: $\beta=2.599, \quad P<0.001$ ) than normotensive subjects. Compared to subjects who ate more than 5 servings of meat per week, those who consumed less than 3 had a higher BMI (girls: $\beta=0.441, P<0.001$; boys: $\beta=0.176, P=0.004)$. Intake of milk and other dairy products, fruit, vegetables, and breakfast also significantly affected BMI (Wald test $P<0.05$; Table 2). 


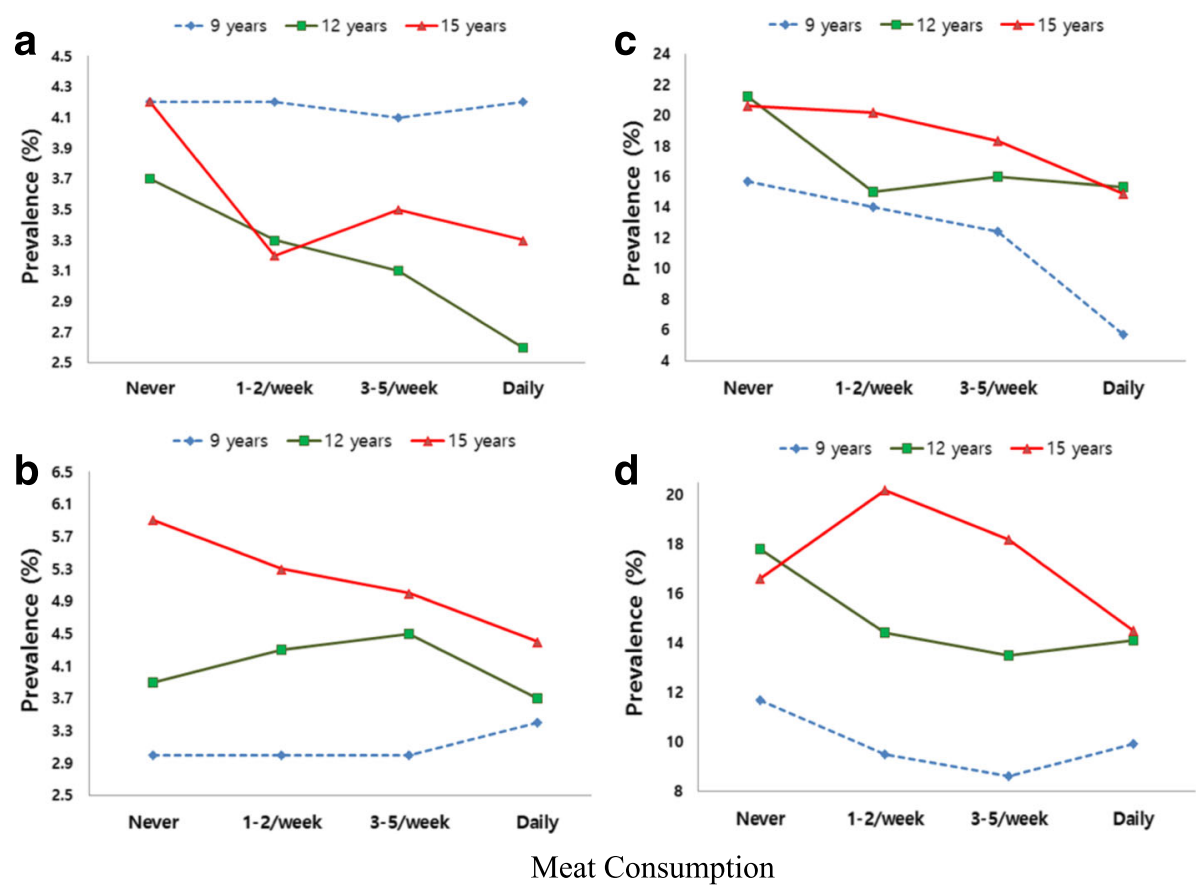

Fig. 1 Prevalence of high blood pressure according to the frequency of meat consumption. By age $(9,12$, and 15 years), the weighted percentage of systolic and diastolic high blood pressure (HBP) in subjects with no excess weight (Panel a: systolic HBP, Panel $\mathbf{b}$ : diastolic HBP, $n=116,475)$ and with obesity (Panel $\mathbf{c}$ : systolic HBP, Panel d: diastolic HBP, $n=9,746$ ) according to the frequency of meat consumption (serving/wk) after adjustment for sex and height. Overall trends are estimated using chi-squared tests. Korea School Health Examination Survey, 2011-2015

\section{Factors associated with blood pressure}

Factors associated with $\mathrm{BP}$, including place of residence, were simultaneously adjusted using multiple linear regression (SBP: $R^{2}=0.260 ; \mathrm{DBP}: R^{2}=0.162$ ) and the results are reported in Table 3 . Obese children and adolescents were estimated to have a higher SBP (+7.49 mmHg; $\beta=7.497, \quad P<0.001)$ and DBP $(+4.12 \mathrm{mmHg} ; \beta=4.123, P<0.001)$ than children and adolescents who had no excess weight. Compared to subjects who ate more than 5 servings of meat a week, those who consumed less than 3 had a higher SBP $(+0.57 \mathrm{mmHg} ; \beta=0.574, P<0.001)$ and $\mathrm{DBP}(+0.37 \mathrm{mmHg}$; $\beta=0.376, P=0.003)$. Those who consumed less than 3 servings of breakfast a week also had a higher DBP (DBP: $\beta=0.202, P=0.035)$ than those who consumed breakfast daily. However, we found that the intake of milk (SBP: $\beta=-0.129, P=0.264$; DBP: $\beta=0.023, P=0.767$ ), fruit (SBP: $\beta=0.143, P=0.189$; DBP: $\beta=-0.128, P=$ 0.098 ), and vegetables (SBP: $\beta=0.044, P=0.661$; DBP: $\beta=0.016, P=0.817)$ were not associated with either SBP or DBP (Table 3).

\section{Associations between meat consumption, obesity, and high blood pressure}

Table 4 displays the results of the multivariate logistic regression. There were significantly increased odds of HBP and obesity in subjects who consumed less than 1 serving of meat a week, compared with those who consumed more than 5 . In a basic Model 1 (adjusted for sociodemographic variables), compared with those who consumed meat more than 5 times a week, subjects who consumed less than 1 serving were significantly more likely to have a higher prevalence of HBP and obesity (systolic HBP: adjusted odds ratio [OR] 1.43, 5\% confidence interval [CI] 1.16-1.75; diastolic HBP: OR 1.37, 95\% CI 1.11-1.69; obesity: OR 1.62; 95\% CI: 1.39-1.91). In Model 2 (further adjusted for BP or BMI when modelling obesity and HBP, respectively), Subjects who consumed meat at a rate of $<1$ serving/wk had significantly increased odds of HBP and obesity compared with those who consumed $>5$ servings/wk. In contrast to the first model, the second model finds an association between HBP and obesity in children and adolescents. The final model indicated that the consumption of less than 1 serving of meat per week was associated with a higher prevalence of HBP (OR for systolic: 1.30; 95\% CI: 1.051.62) and obesity (OR: 1.44; 95\% CI: 1.21-1.70), compared with the consumption of meat at a rate of more than 5 servings a week.

In summary, a statistically significant association was found at all levels of adjustment. The less meat subjects ate, the greater the likelihood of exhibiting HBP and obesity $(P<0.05)$. In this analysis, the ORs of HBP and obesity in children and adolescents fell as the frequency 
Table 2 Adjusted coefficients of regression parameters for BMI in relation to meat consumption

\begin{tabular}{|c|c|c|c|c|c|c|c|c|}
\hline \multirow{3}{*}{$\begin{array}{l}\text { Merged 2011-2015 } \\
(n=136,739) \\
\text { Variables }^{\mathrm{d}, \mathrm{e}}\end{array}$} & \multicolumn{8}{|c|}{ Body Mass Index, $\mathrm{kg} / \mathrm{m}^{2}$} \\
\hline & \multicolumn{4}{|l|}{ Girls $^{b}$} & \multicolumn{4}{|l|}{ Boys $^{b}$} \\
\hline & $\bar{\beta}$ & SEM & $P$-value ${ }^{c}$ & $R^{2}$ & $\bar{\beta}$ & SEM & $P$-value ${ }^{c}$ & $R^{2}$ \\
\hline Adjusted $R^{2}$ & & & & 0.231 & & & & 0.191 \\
\hline \multicolumn{9}{|l|}{ Age (years) } \\
\hline $12 y$ & 0.442 & 0.06 & $<0.001$ & & -0.665 & 0.07 & $<0.001$ & \\
\hline $15 y$ & 1.557 & 0.08 & $<0.001$ & & -0.847 & 0.10 & $<0.001$ & \\
\hline Height (cm) & 0.099 & 0.01 & $<0.001$ & & 0.121 & 0.01 & $<0.001$ & \\
\hline \multicolumn{9}{|l|}{ Areas } \\
\hline Rural & -0.084 & 0.05 & 0.095 & & -0.071 & 0.04 & 0.130 & \\
\hline Blood pressure $(\mathrm{mmHg})$ & 0.795 & 0.01 & $<0.001$ & & 0.116 & 0.01 & $<0.001$ & \\
\hline Systolic hypertension & 1.878 & 0.11 & $<0.001$ & & 2.599 & 0.10 & $<0.001$ & \\
\hline Diastolic hypertension & 0.728 & 0.11 & $<0.001$ & & 1.314 & 0.11 & $<0.001$ & \\
\hline \multicolumn{9}{|l|}{ Dietary patterns (<3/wk) } \\
\hline Meat & 0.441 & 0.05 & $<0.001$ & & 0.176 & 0.06 & 0.004 & \\
\hline Milk & -0.296 & 0.04 & $<0.001$ & & -0.302 & 0.04 & $<0.001$ & \\
\hline Fruits & 0.434 & 0.04 & $<0.001$ & & 0.222 & 0.04 & $<0.001$ & \\
\hline Vegetable & -0.100 & 0.04 & 0.018 & & -0.208 & 0.04 & $<0.001$ & \\
\hline Breakfast & 0.327 & 0.05 & $<0.001$ & & 0.148 & 0.06 & 0.021 & \\
\hline \multicolumn{9}{|l|}{ Physical and leisure activities } \\
\hline Exercise (<3/wk) & -0.329 & 0.04 & $<0.001$ & & 0.056 & 0.03 & 0.097 & \\
\hline Internet or games ( $\geq 2 \mathrm{hr} / \mathrm{d}$ ) & 0.271 & 0.04 & $<0.001$ & & 0.263 & 0.04 & $<0.001$ & \\
\hline
\end{tabular}

${ }^{a}$ Cross-sectional data from the Korea School Health Examination Survey (2011-2015, 1761 schools)

'Outcome variables: Body mass index (BMI)

' $P$-value of Wald's test; $\beta$, coefficient of regression parameters; SEM, standard error of the mean; $R^{2}$, coefficient of determination

${ }^{\mathrm{d}}$ All variables in the left column of the table are explanatory variables, and their associations (including place of residence, 17 cities and provinces in South Korea) with BMI were simultaneously adjusted using multiple linear regression

${ }^{e}$ Reference group: Aged 9 y =0; Urban areas = 0; Dietary patterns, food intake $>5$ servings $/ \mathrm{wk}=0$; Exercise $\geq 5 / \mathrm{wk}=0$; Internet or games $<2 \mathrm{hr} / \mathrm{d}=0$

of meat consumption increased after adjustment for covariates related to HBP.

\section{Discussion}

In our study involving 136,739 children and adolescents of 9, 12, and 15 years of age who participated in the Korea School Health Examination Survey from 2011 through 2015, a higher level of red meat and chicken consumption was associated with lower prevalence of HBP and obesity after adjusting for potential confounding variables. In addition, a higher prevalence of HBP was associated with obesity.

HBP increases the risk of long-term cardiovascular disease, as well as the risk of health complications and death in adulthood [38]. Therefore, there is a need to prevent HBP and obesity in childhood. In this study, $7.7 \%$ of the children and adolescents in the survey had HBP. A previous study has reported that the prevalence of HBP in adolescents across a number of countries was $11.2 \%$ (13\% for boys and 9.6\% for girls) [39], meaning South Korea adolescents have a relatively low HBP rate. In the present study, BP varied with age, height, BMI, and gender, meaning these variables are likely to influence the risk of HBP. For example, boys had a higher prevalence of HBP than did girls. These results were consistent with those of previous studies $[12,35,40,41]$.

We found that children and adolescents who rarely consumed meat had a higher rate of both HBP and obesity compared with those who ate meat daily. Our study demonstrated that obesity in children and adolescents is associated with an increased prevalence of HBP. Even when our analysis controlled for BMI and other potential confounding factors, we found that HBP was more common in those children and adolescents with lower meat consumption.

Red meat and chicken provide a rich source of protein of high biological value and essential nutrients when included as part of a healthy and varied diet [22]. A recent report from the Beef in an Optimal Lean Diet (BOLD) study showed that an increase in lean-beef consumption while controlling saturated fatty acid intake (6\% of total calories) in the context of a heart-healthy diet was associated with significant decreases in total cholesterol and 
Table 3 Adjusted coefficients of regression parameters for blood pressure in relation to meat consumption

\begin{tabular}{|c|c|c|c|c|c|c|c|c|}
\hline \multirow{3}{*}{$\begin{array}{l}\text { Merged 2011-2015 } \\
(n=136,739) \\
\text { Variables }^{\mathrm{d}, \mathrm{e}}\end{array}$} & \multicolumn{8}{|c|}{ Blood pressure (BP), mmHg } \\
\hline & \multicolumn{4}{|c|}{$\overline{\text { Systolic BP }}$} & \multicolumn{4}{|c|}{ Diastolic $\mathrm{BP}^{\mathrm{b}}$} \\
\hline & $\bar{\beta}$ & SEM & $P$-value ${ }^{c}$ & $R^{2}$ & $\bar{\beta}$ & SEM & $P$-value ${ }^{c}$ & $R^{2}$ \\
\hline$\overline{\text { Adjusted } R^{2}}$ & & & & 0.260 & & & & 0.162 \\
\hline \multicolumn{9}{|l|}{ Sex } \\
\hline Boys & 1.137 & 0.11 & $<0.001$ & & 0.467 & 0.07 & $<0.001$ & \\
\hline \multicolumn{9}{|l|}{ Age (years) } \\
\hline $12 y$ & 1.339 & 0.29 & $<0.001$ & & 0.896 & 0.20 & $<0.001$ & \\
\hline $15 y$ & 2.964 & 0.33 & $<0.001$ & & 2.111 & 0.22 & $<0.001$ & \\
\hline Height $(\mathrm{cm})$ & 0.260 & 0.01 & $<0.001$ & & 0.103 & 0.01 & $<0.001$ & \\
\hline \multicolumn{9}{|l|}{ Areas } \\
\hline Rural & -0.089 & 0.28 & 0.757 & & -0.003 & 0.19 & 0.987 & \\
\hline $\mathrm{BMI}\left(\mathrm{kg} / \mathrm{m}^{2}\right)$ & 0.795 & 0.01 & $<0.001$ & & 0.116 & 0.01 & $<0.001$ & \\
\hline Overweight & 4.452 & 0.13 & $<0.001$ & & 2.265 & 0.09 & $<0.001$ & \\
\hline Obesity & 7.497 & 0.16 & $<0.001$ & & 4.123 & 0.10 & $<0.001$ & \\
\hline \multicolumn{9}{|l|}{ Dietary patterns (<3/wk) } \\
\hline Meat & 0.574 & 0.16 & $<0.001$ & & 0.376 & 0.12 & 0.003 & \\
\hline Milk & -0.129 & 0.17 & 0.264 & & 0.023 & 0.07 & 0.767 & \\
\hline Fruits & 0.143 & 0.10 & 0.189 & & -0.128 & 0.07 & 0.098 & \\
\hline Vegetable & 0.044 & 0.09 & 0.661 & & 0.016 & 0.07 & 0.817 & \\
\hline Breakfast & 0.240 & 0.13 & 0.065 & & 0.202 & 0.09 & 0.035 & \\
\hline \multicolumn{9}{|l|}{ Physical and leisure activities } \\
\hline Exercise (<3/wk) & 0.058 & 0.10 & 0.567 & & 0.134 & 0.06 & 0.047 & \\
\hline Internet or games ( $\geq 2 \mathrm{hr} / \mathrm{d}$ ) & 0.077 & 0.11 & 0.490 & & 0.006 & 0.07 & 0.930 & \\
\hline
\end{tabular}

${ }^{a}$ Cross-sectional data from the Korea School Health Examination Survey (2011-2015, 1761 schools)

${ }^{b}$ Outcome variables: SBP or DBP

${ }^{c} P$-value of Wald's test; $\beta$, coefficient of regression parameters; SEM, standard error of the mean; $R^{2}$, coefficient of determination

${ }^{\mathrm{d}}$ All variables in the left column of the table were explanatory variables, and their associations (including place of residence, 17 cities and provinces in South Korea) with SBP or DBP were simultaneously adjusted using multiple linear regression

${ }^{e}$ Reference group: Girls =0; Aged $9 \mathrm{y}=0$; Body mass index (BMI), No excess weight $=0$; Urban areas $=0$; Dietary patterns, food intake $>5$ servings $/$ wk $=0$;

Exercise $\geq 5 / \mathrm{wk}=0$; Internet or games $<2 \mathrm{hr} / \mathrm{d}=0$

low-density lipoprotein cholesterol (LDL-C) in healthy men and women (30-65 years of age) with elevated LDL-C concentrations [16]. In the BOLD study, SBP decreased by $4 \mathrm{~mm} \mathrm{Hg}$ after the consumption of a Dietary Approaches to Stop Hypertension (DASH) diet that included $153 \mathrm{~g}$ of lean beef per day but did not decrease after DASH diets with $113 \mathrm{~g}$ or $28 \mathrm{~g}$ of lean beef per day [23]. It has also been found that a moderate protein DASH diet including lean beef or lean pork decreased SBP in normotensive individuals $[15,23]$.

We observed that children and adolescents with a higher frequency of meat consumption per week had lower BP and BMI and were taller. Westerterp-Plantenga et al.[24] have described that dietary protein contributes to the treatment of obesity and metabolic syndrome by acting on the relevant metabolic targets of satiety and energy expenditure in a negative energy balance, thereby preventing the weight-cycling effect. Meat consumption may be a useful component of weight-loss diets because of the satiating effect of its high protein content [22]. To date, previous studies on BP have tended to focus on adults, including the elderly $[12,18]$. However, our study focuses on children and adolescents. Children and adolescents, who are at a stage of rapid growth and development, exhibit large differences in BP depending on sex, age, and height and have different nutritional needs than adults do [7]. Therefore, the negative association between meat consumption and HBP risk in our study did not agree with observations reported in previous studies $[12,18]$, nor the recommendations of the DASH diet, which encourages lower consumption of red meat [15]. In addition, we found that the consumption of dairy and fruit did not significantly affect $\mathrm{BP}$ after adjusting for potential confounding factors. A low intake of meat, especially red meat, is recommended to avoid the risk of cancer and metabolic syndrome [42]. However, this advice does not consider the fact that meat provides important nutrients for the health, growth, and development of children and adolescents [25, 43, 44]. Red 
Table 4 Association between meat consumption and both obesity and high blood pressure in South Korean children and adolescents

\begin{tabular}{|c|c|c|c|c|}
\hline \multirow{2}{*}{$\begin{array}{l}n=136,739 \\
\text { Aged } 9,12 \text {, and } 15 y\end{array}$} & \multicolumn{4}{|c|}{ Consumption of meat (servings/wk) } \\
\hline & $\overline{<1}$ & $1-2$ & $3-5$ & $>5$ \\
\hline \multicolumn{5}{|l|}{ Obesity $^{a}$, ORs $(95 \% \text { Cl) })^{b}$} \\
\hline Model 1, multivariable ${ }^{d}$ & $1.62^{* * *}(1.39-1.91)$ & $1.42^{* * *}(1.28-1.59)$ & $1.16^{* *}(1.04-1.29)$ & Reference \\
\hline Model 2, model 1 plus BPe & $1.50^{* * *}(1.27-1.76)$ & $1.36^{* * *}(1.21-1.52)$ & $1.13^{*}(1.01-1.26)$ & Reference \\
\hline Model 3, model 2 plus dietary patterns ${ }^{f}$ & $1.43^{* * *}(1.21-1.69)$ & $1.30^{* * *}(1.16-1.46)$ & $1.12^{*}(1.00-1.25)$ & Reference \\
\hline Model 4, model 3 plus activities ${ }^{9}$ & $1.44^{* * *}(1.21-1.70)$ & $1.30^{* * *}(1.16-1.46)$ & $1.12^{*}(1.00-1.25)$ & Reference \\
\hline \multicolumn{5}{|l|}{ Systolic HBP, ORs $(95 \% \mathrm{Cl})^{\mathrm{b}}$} \\
\hline Model 1, multivariable ${ }^{d}$ & $1.43^{* * *}(1.16-1.75)$ & $1.23^{* *}(1.08-1.41)$ & $1.10(0.96-1.26)$ & Reference \\
\hline Model 2, model 1 plus BMl & $1.29 * *(1.04-1.60)$ & $1.14(0.99-1.31)$ & $1.06(0.92-1.22)$ & Reference \\
\hline Model 3, model 2 plus dietary patterns ${ }^{f}$ & $1.31^{* *}(1.06-1.62)$ & $1.15^{*}(1.00-1.32)$ & $1.06(0.92-1.22)$ & Reference \\
\hline Model 4, model 3 plus activities ${ }^{9}$ & $1.30 * *(1.05-1.62)$ & $1.15^{*}(1.00-1.31)$ & $1.05(0.92-1.21)$ & Reference \\
\hline \multicolumn{5}{|l|}{ Diastolic HBP ${ }^{a}$, ORs $(95 \% \mathrm{Cl})^{\mathrm{b}}$} \\
\hline Model 1, multivariable ${ }^{d}$ & $1.37^{* *}(1.11-1.69)$ & $1.27^{* * *}(1.11-1.45)$ & $1.19^{* *}(1.04-1.36)$ & Reference \\
\hline Model 2, model 1 plus BMl & $1.28^{*}(1.03-1.59)$ & $1.20 *(1.04-1.38)$ & $1.16^{*}(1.16-1.33)$ & Reference \\
\hline Model 3 , model 2 plus dietary patterns ${ }^{\mathrm{f}}$ & $1.26^{*}(1.02-1.55)$ & $1.20 * *(1.04-1.38)$ & $1.17^{*}(1.02-1.33)$ & Reference \\
\hline Model 4, model 3 plus activities ${ }^{9}$ & $1.25^{*}(1.02-1.54)$ & $1.19^{* *}(1.04-1.37)$ & $1.16^{*}(1.01-1.33)$ & Reference \\
\hline
\end{tabular}

${ }^{\mathrm{a} O u t c o m e}$ variables: High blood pressure (HBP) or Obesity

${ }^{b *} P<0.05 ;{ }^{* *} P \leq 0.01 ;{ }^{* * *} P \leq 0.001$, using binary multiple logistic regression analysis for adjusted odds ratios (ORs) and $95 \%$ confidence interval (CI)

${ }^{c}$ Explanatory variable: meat consumption (servings per wk)

${ }^{\mathrm{d}}$ Adjusted for sex, age, height, and regions (17 cities and provinces in South Korea)

${ }^{\text {e}}$ Additional adjustment for BP ( $\mathrm{mm} \mathrm{Hg}$ ) when modelling obesity and for BMI $\left(\mathrm{kg} / \mathrm{m}^{2}\right)$ when modelling HBP

${ }^{f}$ Additional adjustment for milk (quartiles), fruit (quartiles), vegetable (quartiles), and breakfast (quartiles)

${ }^{9}$ Additional adjustment for physical activities and internet/games use

meat including beef, pork, and lamb has been an important part of the human diet throughout human evolution [22]. In particular, meat is one of the most nutrient-dense sources of protein, providing iron, vitamin B12, other B complex vitamins, zinc, selenium, and phosphorus $[20,25,43]$. Dietary protein also contributes to the improvement of body composition and lipid and lipoprotein profiles, and the treatment of obesity and metabolic syndrome [24, 45]. Despite these advantages, epidemiological studies have linked meat consumption to HBP [25, 43], with red meat consumption in particular commonly considered a risk factor in HBP because of its saturated fat and cholesterol content [18]. However, these studies have many limitations [25], including that the existing studies are on adults and that other mechanisms may take place in children. Although previous epidemiological data have revealed a possible association between meat consumption and the increased risk of cancer and cardiovascular and metabolic disease [17, 19, 42, 46-49], moderate meat consumption of up to $\sim 100 \mathrm{~g} /$ day was not associated with increased mortality from ischemic heart disease, stroke, or cardiovascular disease of all types among Japanese men and women [26]. According to the OECD, meat consumption (beef and veal, pork, poultry, and sheep) in Asian countries in 2015 (9.6 kg per person in Korea and 6.7 in Japan) is significantly lower than in North and South America $(24.7 \mathrm{~kg}$ per person in the United
States, 40.4 in Argentina, and 46.4 in Uruguay) [50]. In our study, meat consumption proved to be a significant factor of the human diet in regions, countries, and ethnic groups in which meat consumption is relatively low.

The strengths of our study are as follows. Our study is the first to investigate meat consumption and its association with HBP and obesity among children and adolescents in a large and nationally representative population in Korea. In addition, a valid sample was extracted using stratified multistage cluster sampling and probability sampling, and is thus an accurate representation of the child and adolescent population in Korea. Furthermore, the subjects visited medical institutions, where an automated BP monitor with a high level of reliability was used to measure BP, and data were obtained from laboratory and physical examinations using standardized protocols to minimize the influence of measurement error. Finally, the descriptive statistics from the separate Korea School Health Examination Survey (KSHES) cycles produced similar frequencies, percentages, and averages each year. The results were found to have a Cronbach's alpha of more than 0.5 , which indicates a high degree of replicability.

However, our study had several limitations. First, this cross-sectional study did not allow us to evaluate the temporal relationship between meat consumption and HBP. Because risk factors and HBP are measured at the 
same time, it is difficult to determine which of the two occurred first, and cause and effect inferences thus could not be made. Second, the subjects visited hospitals in their neighborhood, and some errors may have occurred in BP measurements due to differences in the BP monitoring equipment used. However, the medical institutions in question adhered to the standard protocols of $\mathrm{BP}$ measurement as recommended by the KSHES, so the results can be considered reliable because the annual measurements produced similar means for BP. Third, socioeconomic status (SES) can influence both BP and obesity but not taken into account here $[8,51]$, because SES indicators (e.g., parental education, parental occupation, and family income) are not included in the standardized questionnaire produced for the KSHES. Finally, meat intake ( $\mathrm{g} /$ day or $\mathrm{g} /$ serving) was not included in the question on food intake in the KSHES questionnaire used in this study. In addition, the question about the frequency of meat consumption did not distinguish between the type of meat (red or white, lean or fatty, and processed or unprocessed) or the type of cooking (e.g., fried or boiled). As a result, this study was unable to assess possible differences in BP resulting from the consumption of different types of meat. However, we found a significant decrease in SBP, DBP, and BMI with increasing meat consumption and a resulting positive effect on the growth of children and adolescents.

\section{Conclusions}

In this nationally representative sample of Korean children and adolescents, we found that meat consumption was inversely associated with HBP and obesity. The odds of HBP were greater among children and adolescents who rarely ate meat compared to those who ate meat daily. An adequate meat intake may therefore contribute to a healthier blood pressure and body weight in children and adolescents.

\begin{abstract}
Abbreviations
95\% Cl: 95\% confidence interval; BMI: Body mass index; DBP: Diastolic blood pressure; HBP: High blood pressure; KSHES: Korea School Health Examination Survey; OR: Odds ratio; SBP: Systolic blood pressure
\end{abstract}

\section{Acknowledgements}

We are grateful to the Ministry of Education of South Korea for allowing us to use the KSHES data. The KSHES on which this study is based was conducted by the Ministry of Education with funding from the Korean Government.

\section{Funding}

We did not receive any funding or support. The Korea School Health Examination Survey (KSHES) on which this study is based was conducted by the Ministry of Education with funding from the Korean Government.

\section{Availability of data and materials}

The KSHESs used in this study are based on official statistics and were obtained as an Excel file with approval (No. 7750, dated September 4, 2016) from the Student Health and Safety Division of the Ministry of Education in response to a request submitted via the Open Information Portal (https://www.open.go.kr/).
The KSHES is conducted every year by the Ministry of Education in accordance with various laws, including the School Health Act (Article 7).

\section{Authors' contributions}

GHK and HSA substantially contributed to the conception and design, and the acquisition, analysis of the data; All authors took part in the interpretation of the data; GHK, HSA, and SWS were conceived of the conception and design of the study; GHK and JYL contributed to the analysis, interpretation of the data, and the identity of those who analyzed the data; HSA, SWS, JSM, and JHH made a final critical revision for important intellectual content; Data collection was designed by SWP, JSM, and JHH. All authors provided critical revisions of the manuscript for important intellectual content; Final approval of the version to be published was approved by HSA, SWS, JYL, and HJK. All authors read and approved the final manuscript.

\section{Competing interests}

The authors declare that they have no competing interests.

\section{Consent for publication}

Not applicable.

\section{Ethics approval and consent to participate}

Approval of the study was obtained from Ethics committees or Institutional Review Boards (IRB: KU-IRB-16-EX-81-A-1) at the University of Korea and the Korean Government. In addition, this survey was conducted according to the guidelines laid down in the Declaration of Helsinki.

\section{Publisher's Note}

Springer Nature remains neutral with regard to jurisdictional claims in published maps and institutional affiliations.

\section{Author details}

'Department of School Health Education, Sanggye High School, 432, Nohaero Nowon-gu, Seoul 01761, Republic of Korea. ${ }^{2}$ Department of Medicine, College of Medicine, Korea University, 73, Inchon-ro, Seongbuk-gu, Seoul 02841, Republic of Korea. ${ }^{3}$ Department of Biostatistics, College of Medicine, Korea University, 73, Inchon-ro, Seongbuk-gu, Seoul 02841, Republic of Korea. ${ }^{4}$ Department of Preventive Medicine, Catholic University of Daegu School of Medicine, 33, Duryugongwon-ro 17-gil, Nam-gu, Daegu 42472, Republic of Korea. ${ }^{5}$ Division of Pediatric Gastroenterolgy, Hepatology and Nutrition, Department of Pediatrics, Seoul National University, Children's Hospital, 101 Daehakro, Jongno-gu, Seoul 03080, Republic of Korea.

${ }^{6}$ Department of Preventive Medicine, College of Medicine, Korea University, 73, Inchon-ro, Seongbuk-gu, Seoul 02841, Republic of Korea.

Received: 16 January 2017 Accepted: 8 May 2017

Published online: 22 May 2017

\section{References}

1. Barba G, Buck C, Bammann K, Hadjigeorgiou C, Hebestreit A, Marild S, Molnar D, Russo P, Veidebaum T, Vyncke $K$, et al. Blood pressure reference values for European non-overweight school children: the IDEFICS study. Int J Obes (Lond). 2014;38 Suppl 2:S48-56.

2. Menghetti E, Strisciuglio P, Spagnolo A, Carletti M, Paciotti G, Muzzi G, Beltemacchi M, Concolino D, Strambi M, Rosano A. Hypertension and obesity in Italian school children: The role of diet, lifestyle and family history. Nutr Metab Cardiovasc Dis. 2015;25:602-7.

3. Rosner B, Cook NR, Daniels S, Falkner B. Childhood blood pressure trends and risk factors for high blood pressure: the NHANES experience 19882008. Hypertension. 2013;62:247-54.

4. Lu X, Shi P, Luo CY, Zhou YF, Yu HT, Guo CY, Wu F. Prevalence of hypertension in overweight and obese children from a large school-based population in Shanghai, China. BMC Public Health. 2013;13:24.

5. Halbach SM, Flynn J. Treatment of obesity-related hypertension in children and adolescents. Curr Hypertens Rep. 2013;15:224-31.

6. Kotsis V, Nilsson P, Grassi G, Mancia G, Redon J, Luft F, Schmieder R, Engeli S, Stabouli S, Antza C, et al. New developments in the pathogenesis of obesity-induced hypertension. J Hypertens. 2015;33:1499-508.

7. Dong J, Guo XL, Lu ZL, Cai XN, Wang HC, Zhang JY, Yan LX, Xu AQ. Prevalence of overweight and obesity and their associations with blood 
pressure among children and adolescents in Shandong, China. BMC Public Health. 2014;14:1080.

8. Bucher BS, Ferrarini A, Weber N, Bullo M, Bianchetti MG, Simonetti GD. Primary hypertension in childhood. Curr Hypertens Rep. 2013;15:444-52.

9. Ndanuko RN, Tapsell LC, Charlton KE, Neale EP, Batterham MJ. Dietary Patterns and Blood Pressure in Adults: A Systematic Review and MetaAnalysis of Randomized Controlled Trials. Adv Nutr. 2016;7:76-89.

10. Safdar NF, Bertone-Johnson ER, Cordeiro L, Jafar TH, Cohen NL. Dietary patterns and their association with hypertension among Pakistani urban adults. Available at: http://apjcn.nhri.org.tw/server/APJCN/24/4/710.pdf. Accessed 3 Jan, 2016.

11. Fekete AA, Giromini C, Chatzidiakou Y, Givens DI, Lovegrove JA. Whey protein lowers blood pressure and improves endothelial function and lipid biomarkers in adults with prehypertension and mild hypertension: results from the chronic Whey2Go randomized controlled trial. Am J Clin Nutr. 2016;104(6):1534-44.

12. Du H, Li L, Bennett D, Guo Y, Key TJ, Bian Z, Sherliker P, Gao H, Chen Y, Yang $L$, et al. Fresh Fruit Consumption and Major Cardiovascular Disease in China. N Engl J Med. 2016;374:1332-43.

13. Asghari G, Yuzbashian E, Mirmiran P, Hooshmand F, Najafi R, Azizi F. Dietary Approaches to Stop Hypertension (DASH) Dietary Pattern Is Associated with Reduced Incidence of Metabolic Syndrome in Children and Adolescents. J Pediatr. 2016;174:178-84. e1.

14. Anil S, Charlton KE, Tapsell LC, Probst Y, Ndanuko R, Batterham MJ. Identification of dietary patterns associated with blood pressure in a sample of overweight Australian adults. J Hum Hypertens. 2016;30:672-8.

15. Sayer RD, Wright AJ, Chen N, Campbell WW. Dietary Approaches to Stop Hypertension diet retains effectiveness to reduce blood pressure when lean pork is substituted for chicken and fish as the predominant source of protein. Am J Clin Nutr. 2015;102:302-8.

16. Roussell MA, Hill AM, Gaugler TL, West SG, Heuvel JP, Alaupovic P, Gillies PJ, Kris-Etherton PM. Beef in an Optimal Lean Diet study: effects on lipids, lipoproteins, and apolipoproteins. Am J Clin Nutr. 2012;95:9-16.

17. Bovalino S, Charleson G, Szoeke C. The impact of red and processed meat consumption on cardiovascular disease risk in women. Nutrition. 2016;32:349-54.

18. Bernstein AM, Sun Q, Hu FB, Stampfer MJ, Manson JE, Willett WC. Major dietary protein sources and risk of coronary heart disease in women. Circulation. 2010;122:876-83.

19. Pereira PM, Vicente AF. Meat nutritional composition and nutritive role in the human diet. Meat Sci. 2013;93:586-92.

20. Agarwal S, Fulgoni 3rd VL, Berg EP. Association of lunch meat consumption with nutrient intake, diet quality and health risk factors in U.S. children and adults: NHANES 2007-2010. Nutr J. 2015;14:128. 14

21. McGuire S. U.S. Department of Agriculture and U.S. Department of Health and Human Services, Dietary Guidelines for Americans, 2010. 7th Edition, Washington, DC: U.S. Government Printing Office, January 2011. Adv Nutr. 2011;2:293-4.

22. Wyness $\mathrm{L}$. The role of red meat in the diet: nutrition and health benefits. Proc Nutr Soc. 2016;75:227-32.

23. Roussell MA, Hill AM, Gaugler TL, West SG, Ulbrecht JS, Vanden Heuvel JP, Gillies PJ, Kris-Etherton PM. Effects of a DASH-like diet containing lean beef on vascular health. J Hum Hypertens. 2014;28:600-5.

24. Westerterp-Plantenga MS, Lemmens SG, Westerterp KR. Dietary protein - its role in satiety, energetics, weight loss and health. Br J Nutr. 2012;108 Suppl 2:S105-12.

25. Klurfeld DM. Research gaps in evaluating the relationship of meat and health. Meat Sci. 2015;109:86-95.

26. Nagao M, Iso H, Yamagishi K, Date C, Tamakoshi A. Meat consumption in relation to mortality from cardiovascular disease among Japanese men and women. Eur J Clin Nutr. 2012;66:687-93.

27. Appel LJ, Giles TD, Black HR, Izzo Jr JL, Materson BJ, Oparil S, Weber MA. ASH position paper: dietary approaches to lower blood pressure. J Am Soc Hypertens. 2010;4:79-89.

28. Funtikova AN, Navarro E, Bawaked RA, Fito M, Schroder H. Impact of diet on cardiometabolic health in children and adolescents. Nutr J. 2015;14:118.

29. Education Ministry. Manual for Korea School Health Examination Survey 20122014. Available at: http://www.schoolhealth.kr/. Accessed March 22, 2015.

30. Education Ministry. Manual for Korea School Health Examination Survey 20092011. Available at: http://www.schoolhealth.kr/. Accessed March 22, 2015.
31. National High Blood Pressure Education Program Working Group on High Blood Pressure in Children and Adolescents. The fourth report on the diagnosis, evaluation, and treatment of high blood pressure in children and adolescents. Pediatrics. 2004;114:555-76.

32. Lee CG, Moon JS, Choi J-M, Nam CM, Lee SY, Oh K, Kim YT. Normative blood pressure references for Korean children and adolescents. Korean J Pediatr. 2008; 51:33. Available at: chrome-extension://oemmndcbldboiebfnladdacbdfmadadm/ http://www.kjp.or.kr/ upload/2008510103-20080140200640.PDF.

33. Barlow SE, Expert C. Expert committee recommendations regarding the prevention, assessment, and treatment of child and adolescent overweight and obesity: summary report. Pediatrics. 2007;120 Suppl 4:S164-92.

34. Moon J, Lee SY, Nam CM, Choi JM, Choe BK, Seo JW, Oh K, Jang MJ, Hwang SS, Yoo MH, et al. 2007 Korean National Growth Charts: reveiw of developmental process and an outlook. Korean J Pediatr. 2008;51:1-25. Available at: chrome-extension://oemmndcbldboiebfnladdacbdfmadadm/ http://www.kjp.or.kr/upload/2008510101-20080140135740.PDF.

35. Afrifa-Anane E, Agyemang C, Codjoe SN, Ogedegbe G, de-Graft Aikins A The association of physical activity, body mass index and the blood pressure levels among urban poor youth in Accra, Ghana. BMC Public Health. 2015;15:269.

36. Higgins JP, Tuttle T, Higgins JA. Altitude and the heart: is going high safe for your cardiac patient? Am Heart J. 2010;159:25-32.

37. Soria R, Egger M, Scherrer U, Bender N, Rimoldi SF. Pulmonary artery pressure and arterial oxygen saturation in people living at high or low altitude: Systematic review and meta-analysis. J Appl Physiol (1985). 2016:121(5):1151-9.

38. Steinberger J, Daniels SR, Hagberg N, Isasi CR, Kelly AS, Lloyd-Jones D, Pate RR, Pratt C, Shay CM, Towbin JA, et al. Cardiovascular Health Promotion in Children: Challenges and Opportunities for 2020 and Beyond: A Scientific Statement From the American Heart Association. Circulation. 2016;134:e236-55.

39. de Moraes AC, Lacerda MB, Moreno LA, Horta BL, Carvalho HB. Prevalence of high blood pressure in 122,053 adolescents: a systematic review and meta-regression. Medicine (Baltimore). 2014;93:e232.

40. Yan WL, Li XS, Wang Q, Huang YD, Zhang WG, Zhai XH, Wang CC, Lee $\mathrm{H}$. Overweight, high blood pressure and impaired fasting glucose in Uyghur, Han, and Kazakh Chinese children and adolescents. Ethn Health. 2015:20:365-75

41. Xi B, Zong X, Kelishadi R, Hong YM, Khadilkar A, Steffen LM, Nawarycz T, Krzywinska-Wiewiorowska M, Aounallah-Skhiri H, Bovet P, et al. Establishing International Blood Pressure References Among Nonoverweight Children and Adolescents Aged 6 to 17 Years. Circulation. 2016;133:398-408.

42. Rohrmann S, Overvad K, Bueno-de-Mesquita HB, Jakobsen MU, Egeberg R, Tjonneland A, Nailler L, Boutron-Ruault MC, Clavel-Chapelon F, Krogh V, et al. Meat consumption and mortality-results from the European Prospective Investigation into Cancer and Nutrition. BMC Med. 2013;11:63.

43. Biesalski HK. Meat as a component of a healthy diet - are there any risks or benefits if meat is avoided in the diet? Meat Sci. 2005;70:509-24.

44. Murphy MM, Spungen JH, Bi X, Barraj LM. Fresh and fresh lean pork are substantial sources of key nutrients when these products are consumed by adults in the United States. Nutr Res. 2011;31:776-83.

45. Layman DK, Clifton P, Gannon MC, Krauss RM, Nuttall FQ. Protein in optimal health: heart disease and type 2 diabetes. Available at: http://ajcn.nutrition. org/content/87/5/1571S.long. Accessed 3 Jan, 2016.

46. Larsson SC, Orsini N. Red meat and processed meat consumption and allcause mortality: a meta-analysis. Am J Epidemiol. 2014;179:282-9.

47. Lajous M, Bijon A, Fagherazzi G, Rossignol E, Boutron-Ruault MC, ClavelChapelon F. Processed and unprocessed red meat consumption and hypertension in women. Am J Clin Nutr. 2014;100:948-52.

48. Lajous M, Tondeur L, Fagherazzi G, de Lauzon-Guillain B, BoutronRuaualt MC, Clavel-Chapelon F. Processed and unprocessed red meat consumption and incident type 2 diabetes among French women. Diabetes Care. 2012;35:128-30.

49. Micha R, Wallace SK, Mozaffarian D. Red and processed meat consumption and risk of incident coronary heart disease, stroke, and diabetes mellitus: a systematic review and meta-analysis. Circulation. 2010;121:2271-83.

50. OECD. Meat consumption (indicator). Available at: https://data.oecd.org/ agroutput/meat-consumption.htm. Accessed on 15 March, 2017.

51. Shrewsbury $V$, Wardle J. Socioeconomic status and adiposity in childhood: a systematic review of cross-sectional studies 1990-2005. Obesity (Silver Spring). 2008;16:275-84. 